\title{
The Dating Game: The Scientific Analysis of Benin Copper-Alloy Art-From TL to ${ }^{21}{ }^{\circ} \mathrm{Pb}$
}

\author{
Joseph Nevadomsky* and Natalie Lawson \\ Department of Anthropology, USA
}

*Corresponding author: Joseph Nevadomsky, Department of Anthropology, USA.

Received Date: September18, 2019

Published Date: November 06, 2019

\section{Abstract}

To determine the age and authenticity of Benin bronzes collectors and curators have turned to scientific analyses for certainty. Galleries increasingly offer every security from TL Dating to spectrography for the Benin objects they advertise. These watertight guarantees for objects that appear stylistically anomalous, even contemporary, have created a stir among art historians who are aware of TL and other methods usually through hearsay and conference scuttlebutt but don't know how they work or what they do. This paper attempts a layman's explorations and a critique for the study of Benin art. The exercise requires a basic knowledge of physics and assumes art historians have had at least a secondary or high school education.

\section{Introduction}

In 1897 the British launched a punitive expedition on the African kingdom of Benin. They returned with thousands of brass and ivory artifacts. Sought after in the art world, these objects command premium auction prices for African art. This applies only to those made before 1897. Not all objects made before 1897 were confiscated, however. Many remained in chieftaincy homes in the city, in the palaces of dukes (Enogie) outside the city, and in rural communities. Occasionally such pieces come on the market. An example is the altar to the hand owned by Chief Ezomo that now resides in the Metropolitan Museum of Art. Further, the brasscasting art tradition in Benin City continues, for tourists, for runners who doctor the pieces to make them look old, and for Nigerians. No wonder that African art dealers are interested in techniques that validate genuine from pieces labeled as "authentic," meaning pre-1897. "The problems of art history in West Africa are almost unique," as Paul Craddock (1985:3) tells us in an essay on dating metals. The Benin copper-alloy objects are one of those problems.

That problem is complex. Keep the following in mind. First is that Benin cast artifacts are typically called "Benin bronzes" but they are now referred to as brass; the composition of a sample of objects at the National Museum of African Art, Smithsonian, Washington, D.C., ranged "from 64 to $94 \%$ copper, 0 to $7 \%$ tin, 1 to $17 \%$ lead, and 0 to $16 \%$ zinc" as well as "small quantities of arsenic, silver, antimony, and nickel" with iron at 0.4 to $5 \%$ Schrenk [1] Copper- alloy is the correct designation, but Benin "bronze" became equated with royal art from Europe early on and stuck for a century at least while brass is now commonly used by art historians.

Second, most Benin cast art has clay core residue as part of the casting cire perdue, "lost wax" casting method. The color of this soil ranges from a red brown laterite color to gray or black burnt clay residue. The clay stuck in crevices is material left over from the casting process, or accumulated dirt from centuries of storage. It is material that can be dated. However, because these objects are made for altars or display, they are rarely connected to excavation sites, where stratigraphy methods and in situ assessments can be made.

Third, while routine cleaning was done by attendants or household help, in most cases this was perfunctory, and the debris of ages took its toll on these objects. Once they were removed from their original setting after 1897, they were subjected to severe cleaning and coatings with oils and waxes, even modern pigments that mimicked a heavy patina. Many of these sometimes-inadvertent alterations were the result of typical cleaning consistent with the $20^{\text {th }}$ century household practices.

Scientifically certified dates from European and American labs are offered as objective indicators to authenticate Benin copperalloy cast objects that are not authentic. The manufacture of 
artificially altered Benin artifacts with scientific documentation is an international cottage industry. The collusion between Benin's casters is a grainy issue, no doubt, with Benin's casters as indifferent or incidental participants. Hausa dealers purchase raw castings and transform them into antiquities and these traders are abetted by international brokers, appraisers and buyers armed with scientific documentation (see Nevadomsky 2004 for details). As Craddock says in his recent book on copies, fakes and forgeries (2009: $3-4$ ), the market is awash with fakes and frauds, and increasingly sophisticated methods of fabrication by forgers. This is echoed by Michel Brent's excursion into the faking of Malian terra-cottas (2001). Given the nature of the market and high-priced auctioned art, that is to be expected.

Art historians rely on stylistic analyses to date and evaluate the Benin copper-alloy castings, and several chronologies have been proposed, with modifications; there are, too, many essays on iconography and ceremonial use. Nevertheless, collectors and curators seek scientific validation because age correlates with value and the forgery of Benin art is a thriving cottage industry.

The upshot is that collectors and curators have turned to scientific analysis for certainty. Galleries increasingly offer every security from TL dating to spectrography for the Benin objects they advertise. These watertight guarantees for objects that appear stylistically anomalous, even contemporary, has created a stir among art historians who are aware of TL and other methods, usually through hearsay and conference scuttlebutt, but don't know how they work or what they do. This paper attempts a layman's exploration and a critique for the study of Benin art. The exercise requires a basic knowledge of physics and assumes art historians have had at least a secondary school education.

\section{T-L Dating}

Until recently, thermoluminescence (TL) had a cult following among collectors. Even now, TL is highly regarded. The technique employs presumably infallible scientific measures to determine object dates from clay (as in pots) or clay residues (as in Benin copper-alloy cores). That certainty is contestable. In 1996, an archaeological team used TL to study human occupation in Australia. Accepted radiocarbon (C-14) dates showed that aborigines occupied Australia about 40-50,000 years ago. TL dates indicated human occupation at 116,000 to 176,000 years ago Lawson [2].
This date created a stir in anthropology. Yet a subsequent TL study put human occupation at 50-60,000 years. This is disconcerting. Although TL has lost its halo in recent years, it remains necessary to understand how it works, and its effectiveness as currently considered. Therefore, to understand the theory behind TL, elementary knowledge of the atom is necessary (Figure 1).

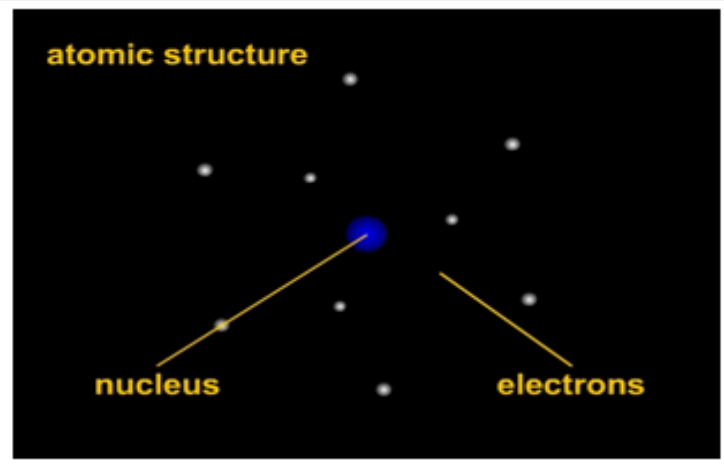

Figure 1: A theoretical model of an atom.

This is a picture of an atom based on mathematical calculations. (This is based on my student Natalie Lawson's [2] SWAA paper. The content and images are from that paper.) The blue center is the nucleus and contains protons (positively charged particles) and neutrons (uncharged particles). Orbiting the nucleus are electrons. Like planets, electrons have specific paths. Negatively charged particles and their movements from normal orbits to excited orbits are important because the movement from one orbit to another is measured in the form of light waves.

So where exactly does (TL) dating come in? Brasses using the lost wax method often contain small amounts of the clay cores. Clay is a mixture of small crystals with elemental impurities. Each crystal is made of atoms such as silicon or hydrogen. Clay crystals atoms are held together in specific arrangements by electrical fields created by the attractive and repulsive interactions of the rotating electrons. But by nature, crystals are not perfect. The atoms suffer a loss of entropy (the randomness they prefer) when they condense and this loss results in defects in the crystal that take several forms: a vacancy caused by the absence of an atom or ion, a vacancy caused by dislocated atoms, or the presence of an atom other than the one that should be there (an impurity). TL dating is concerned with the first two imperfections because it is in the vacant areas that electrons can become trapped (Figure 2).
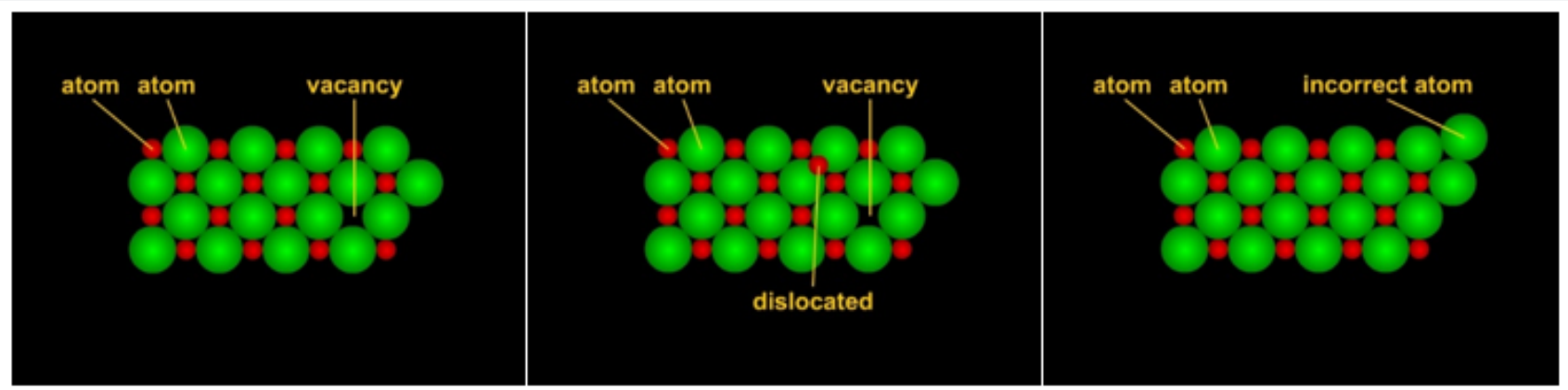

Figure 2: Crystal imperfections. 
When crystals are exposed to ionizing radiation, electrons may be trapped within these defects. Some electrons remain trapped, occupying a space meant for an entire atom. "Vacant" sites that contain electrons instead of atoms are called F centers. TL dating utilizes the properties of the $\mathrm{F}$ center electrons. A thorough explanation of this can be found on the Quaternary Surveys website, a detailed professional explanation from a lab that conducts TL testing. There are similar labs that conduct TL and others tests on metals, however.

How does ionizing radiation work? Radiation is the propagation of electrons from point to point through space or matter. This energy can be moved two ways: (1) via particulates such as electrons, alpha particles, beta particles, gamma particles, or neutrons or by (2) electromagnetic waves such as light. TL dating is concerned with ionizing radiation. Ionizing radiation contains sufficient energy to move electrons (Figure 3).

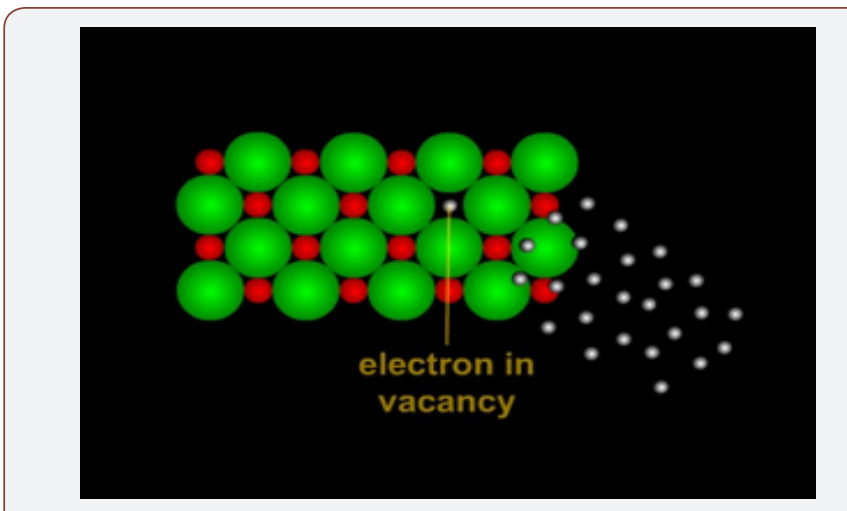

Figure 3: An $\mathrm{f}$ center and ionizing radiation.

Non-ionizing radiation does not possess enough energy to move electrons. Examples of non-ionizing radiation include low power lasers like retinal scanners and exempt lasers such as grocery store scanners. Ionizing radiation sources are much stronger and, among other industrial uses, are found in power reactors (about 1000 mega Curies) and Geiger counter calibration sources (1-3 Curies). Ionizing radiation can get extremely strong. For example, the catastrophe at Chernobyl put out between 80 and 100 million Curies of ionizing radiation. The meltdown at Chernobyl set off alarms at a power plant in Sweden.

Where does the radiation studied in TL dating come from? Usually it is natural radiation. Natural radiation can come from different sources. Because most Benin bronzes were not buried, impurities of radioactive elements within the clay core itself are the major contributors to the total content of radiation. Uranium, thorium, and potassium are very common impurities in clay. These elements are radioactive. They do not have a stable nucleus and they lose protons and neutrons until they reach a stable state. They emit alpha, beta, and gamma rays when they decay. The time over which the unstable nucleus decays to half its original form is the half-life. (Half of the original molecules remain; the other half decays into different elements--potassium into argon, strontium into rubidium, Carbon-14 into Carbon-13.) Each radioactive element has a specific and known half-life. If the brass object had been buried, additional contamination would come from the soil.

At ambient temperature, the crystals hold the electrons in the sites. At high temperatures, though, the electrons are released from their various sites and higher energy states and return to where they belong, releasing their stored energy and giving off a luminescent glow as they leave the vacant site and return to their ground state. The slate has been wiped clean. When the copper-alloy is cast, the clay in the core is heated and the slate is cleaned (Figure 4).

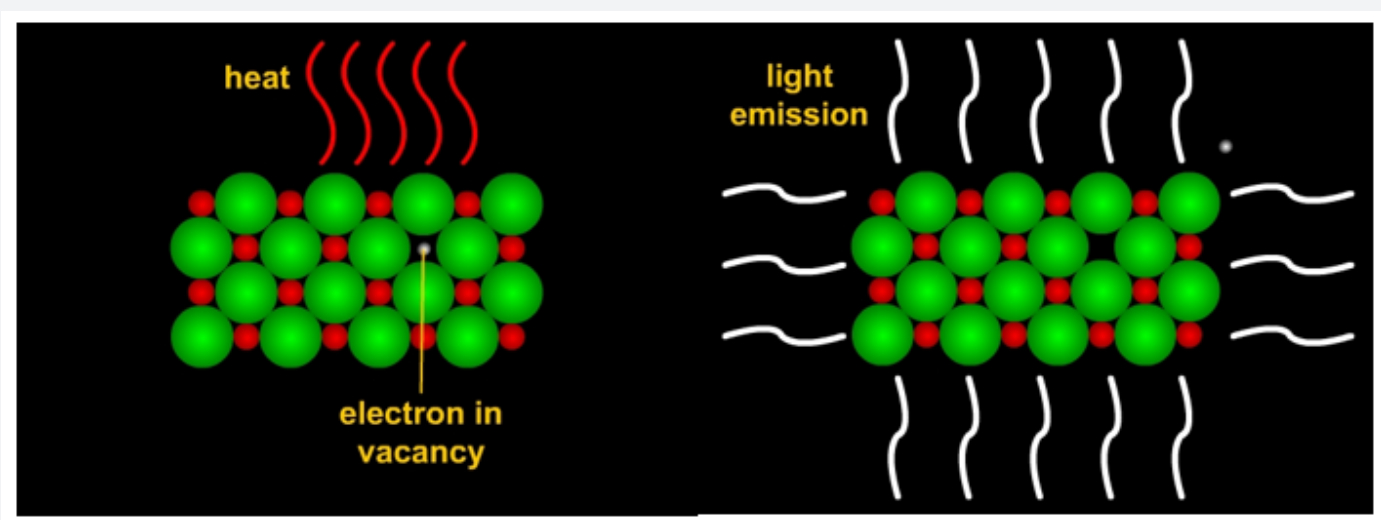

Figure 4: Crystal is heated, and the electron is released, giving off light.

The impurities still in the clay core begin to move radiation through the crystals again. If the copper-alloy is buried, the contaminants in the soil also move radiation through the crystals. So, electrons once again move into the vacancies at the rate of decay of the radioactive elements in the clay and become trapped in the sites created by imperfections within the atoms. All this activity, though, occurs after the copper-alloy has been cast. Thus, when a sample is taken, it is possible to determine how many years ago the copper-alloy object was cast by the amount of light given off from a clay sample.

How does the movement of electrons translate into a TL date? It works the same way as when the brass is cast, and the electrons are returned to their ground states. Except when the sample is heated, the amount of light released from the electrons leaving the F centers is measured. If the total radiation dose is known, (the radiation from the sample as well as the radiation content of the 
ground), it is possible to use these measurements to determine the last time the slate was cleaned (Figure 5).

Hopefully, that date would be the date of casting. The age of casting can be determined using this equation:

Age of event (in years) = Palaeodose (total exposure from date of casting)/ Annual Radiation Dose

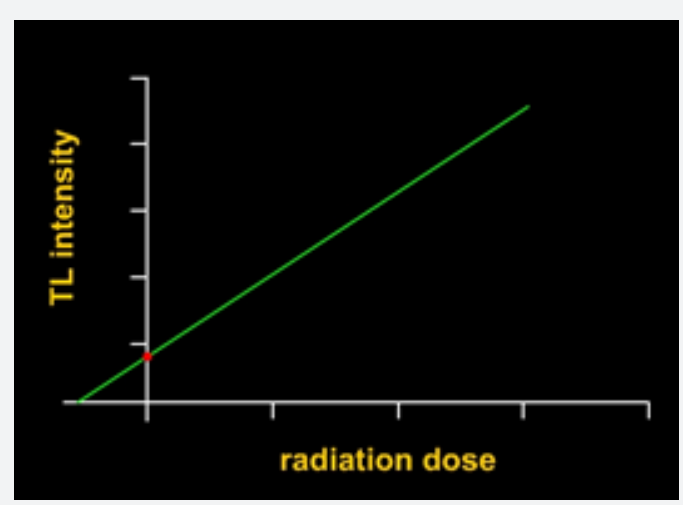

Figure 5: Finding a TL date. Source: quaternary surveys website.

\section{Problems in T-L Dating}

It is possible to analyze a sample and find a date younger than the actual one. Remember, when the trapped electrons are exposed to enough heat they are released. Heat can 'reset' the TL clock. Recently, a museum in Liverpool T-L dated Benin pieces from their collection. The TL's dated to the 1940's. Reviewing the history of the Benin brass in their collection, the curators found that the pieces were in the museum basement at the time of an air raid fire (Craddock 2009: 112) Goedicke [3]. Heating copper-alloy objects during repair has the same effect; clay residue in copper-alloy can register younger dates because of repairs of cracks and missing pieces. Prolonged exposure to the sun can also lower the TL date Craddock and Picton [4]. This is important to note because most Benin objects were displayed as shrine ornaments.

A serious concern for collectors is a sample analysis that gives a date older than the actual one. TL dating, like the radiocarbon method, may give a false ancient date. Forgers place crushed ancient terracotta inside a copper-alloy object. "TL authenticity certificates have been issued for stylistically poor bronze objects where the presence of a legitimate core was unlikely" Craddock [5]; (see also Craddock 2009:115-7). Forgers also utilize X-ray machines to bombard clay cores with radiation. A contact in the art world confided that he placed faked pottery under an X-ray machine overnight. His brother is a dentist. However, in all likelihood this is hyperbole as it would "be difficult to irradiate to any extent and get a kind of uniformity of radiation" Bortolot [6]; results would give variable rates also and is a hit or miss method, mostly miss. Further, dental x-rays are normally too weak to bring such changes about and /or too narrowly focused. Bombarding objects, especially clay based objects, with X- or gamma rays need to be uniformly irradiated and would involve an enormous expenditure of time, not to mention calculating doses necessary to mimic a age Brent [7]. Cast objects x-rayed at airport checkpoints are not strong enough to alter dates, either. X-rays to assess restorations to disguise severe damage also are unlikely to alter the TL date.

The clay core sample must be unpolluted. For accuracy, a sample should be drawn from uncontaminated clay, by drilling into a part of the core that has not been exposed to the environment since casting. Environmental factors are important. TL dates of pots or objects removed in situ from archaeological excavations produce good dates because the environment itself can be sampled in the context of soil strata, the TL date serving as a backup to stratigraphy. Also, objects found in situ are often in an environment of objects that can also be tested for uniformity.

However, where the burial environment is unknown, or the objects are displayed above ground, estimates of real age are problematic. Willett and Fleming [8] include a catalogue of bronze testing that gives a listing of problems encountered with TL testing. Many of the pieces included have no more than a vestige amount of soil to establish an environmental dose rate. About $3 / 4 \mathrm{~s}$ of the Benin castings in this catalogue had no clay residue to test. The core self-dose is estimated to be between 10 and $20 \%$ of what the dose rate of a sample of infinite size. This percentage is calculated from measuring the amount of clay core around the sampling area Willett and Fleming [8]. Whether or not these estimations are correct is unclear and the artifacts tested in this manner are suspect (Willett and Fleming: ibid). Benin castings fall into this category. Although TL dating is for pots and ceramics, it is fraught with problems regarding dating. One trick, widely employed in Latin America, is to use an ancient pottery shard as the base of the pot and molding a faked pot on top. Forgers know that the base is the most obvious place for removing a clay sample for analysis because it is not easy to detect, can be plugged after testing, and rarely has any designs that would detract from its curatorial value. Bortolot (2002) confided that some Benin castings he tested had artificial cores made of powdered pottery and charcoal Brent [7]. The TL tests gave a date of about 700 years old, so fit the stylistic timeline for the type of casting heads, but the castings themselves seemed somehow off. Also, the TL curves of the 8 objects he tested were "too good for Nigerian cores and they were all exactly the same so that you could overlay them." Upon further inspection, he found that the reddish core residue was 700-year-old French brick. Craddock mentions similar cases (2009:117).

\section{XRD, SEM, GLC}

Most metals oxidize over time. Rust is the oxidizing of iron. When copper oxidizes it forms a thin layer of copper oxide, greenish in color and is called patina, so appealing that copper is a popular metal for use in decorative projects. Normal oxidation of brass or bronze is a green layer of a stable mineral. True oxidation of brass meshes with the metal. Benin brasses are a mixture of copper, lead, zinc, and tin plus metallic impurities; these oxidize and a patina forms over time. The patina can be studied with X-ray diffraction (XRD), scanning electron microscopy (SEM), and gas liquid chromatography (GLC). 


\section{X-Ray Diffraction (XRD)}

X-ray diffraction works much like a microscope. Like thermoluminescence it utilizes crystal structures. X-rays have a very high energy (i.e., the capacity to produce change). They also penetrate matter. XRD studies the scatter and diffraction patterns created when crystal structures are bombarded with X-rays. The results show where the electrons in the crystal structure interfered with the X-rays. It is a magnified picture of the crystal structure. Scientists use these 'pictures' of the scattered X-rays to determine the electron densities. Denser groupings of electrons occur near the centers of the atoms and the amount of X-ray diffraction shows the groupings. The position of the nucleus of the atom, bond lengths, and bond angles (a molecule's geometric parameters) are then established. The geometric parameters are unique to each different element or molecule.

\section{Scanning Electron Microscopy (SEM)}

Scanning electron microscopy studies the adhesion and composition of patinas. Like the XRD, the SEM operates like a microscope (Feucht, SEM). The SEM bombards the surface with electrons. Using magnetic lenses and metal apertures the stream of accelerated electrons is focused on the sample until the beam is monochromatic. Three different signals result from the collisions between these electrons and the electrons in the actual patinas: (1) secondary electrons, (2) backscattered electrons, (3) and x-rays (SEM).

Secondary electrons are the electrons of the molecules within the patina. Their bombardment from the SEM knocks them from their normal orbits. The SEM detects these inelastic changes and monitors the angle at which the electrons in the patina are moved from their orbits, and creates a high-resolution image (Feucht, SEM). The adhesion, the space between the patina and the brass, is viewed: poor adhesion indicates a forgery, and good adhesion usually a genuine object.

Backscattered electrons are the beam electrons. The amount of backscattered electrons detected by the SEM depends on the atomic numbers of elements that make up the patina. An element's atomic number is the unique number of protons (positively charged particles) in its nucleus.

\section{Gas Liquid Chromatography (GLC)}

Gas liquid chromatography analyzes components of samples. Forensic laboratories utilize GLC with non-selective detectors (a detector that responds to all compounds and elements except the carrier gas to analyze unknown samples collected at crime scenes. A gas chromatography (GLC) tells a scientist what compounds an unknown sample contains. Organic laboratories use GLC to measure concentrations of known organic samples such as formaldehyde.

Every molecule has different properties and chromatography takes advantage of that. Some compounds are polar with a strong positive charge (a desire to gain electrons) at one end of the compound and a strong negative charge (a desire to give electrons) at the other. Some are non polar; their charges are balanced. The degree of polarity depends upon what elements the compound contains and their location. A compound with an oxygen molecule on one end and a carbon molecule on the other is more polar than a compound that has an oxygen and hydrogen on one end and a carbon on the other.

GLCs have different types of detectors: non selective (responds to all compounds except the carrier gas), selective (responds to a certain type of compounds), and specific (only a specified compound). Patinas are studied with non-selective detectors. A sample is vaporized and syringe injected into a chromatography column, and then pushed through the column by an inert (nonreactive) gas. As the sample moves through the column, different compounds are sorted out. For example, polar compounds move slowly because they are more attracted to the compounds within the column. Non-polar compounds move faster because they are not attracted to the compounds within the column. The compounds are identified by their retention times: the time it takes the compound to move through the column. An alcohol $(-\mathrm{OH})$ that is quite polar will have a retention time different than a double bonded carbon $(\mathrm{C}=\mathrm{C})$ that is non polar. An aldehyde (-CHO) will have a different retention time than a cyanide bond $(\mathrm{C} \equiv \mathrm{N})$. And so on.

True patinas contain certain compounds. Cuprite $\left(\mathrm{Cu}_{2} \mathrm{O}\right)$, carbonate chloride or carbonate sulphate are formed during the oxidation of copper. When buried, copper also oxidizes to form green malachite $\left(\mathrm{Cu}_{2}(\mathrm{OH})_{2} \mathrm{CO}_{3}\right)$ and sometimes, azurite $\left(\mathrm{Cu}(\mathrm{OH})_{2}\left(\mathrm{CO}_{3}\right)_{2}\right)$. If a salt is present, a chloride may be formed. Pollution causes the creation of brochantite $\left(\mathrm{Cu}_{4}\left(\mathrm{SO}_{4}\right)(\mathrm{OH})_{6}\right)$ or antlerite $\left(\mathrm{Cu}_{3}\left(\mathrm{SO}_{4}\right)(\mathrm{OH})_{4}\right)$ (Craddock, 5). A sample of a patina can be scraped off the bronze, dissolved, and injected into the GLC. The gas chromatograph analyzes the sample and the scientist determines if the above compounds are present or if there are suspicious compounds.

\section{Patination}

The analysis of patinas on Benin copper-alloys is problematic. Copper-alloys stood on exposed altars, servants polished hip masks to retain luster; Nigerians nowadays prefer bright and shiny statues that houseboys periodically clean. After their sale to offset expenses, some expeditionary objects received waxes that do not represent the original aesthetic. Several objects in the PittRivers collection had been treated with neat's feet oil to prevent damaging corrosion. Objects in the National Museum of African Art were coated with cadmium pigments (not available until after 1925), Prussian blue pigment, a black waxy coating, emerald green, arsenic, and other inappropriate materials (Schrenk, 1994:55). When an Early Period Head was purchased by Sotheby's in 1963 William Fagg persuaded the new owner to have the rent in the chin and cheek repaired. Although a laborious task, it was successfully done, with a small panel of metal annealed to fill the space. The heating process destroyed the original patina, so a painted patina replaced it, later replaced by a more natural dark coppery patina as evident when it was auctioned by Christie's (Christie's Tribal Art 1989: 45) to a private Swiss collector for the then princely sum of 
$£ 1.3$ million, a record for tribal art at the time (The Daily Telegraph, July 5, 1989: 19).

The composition of the patina and the adhesion of the patina to the copper-alloy are important. A faked patina often contains the wrong minerals such as copper nitrate, a substance that does not occur naturally Craddock [4]. Faked patinas are often incompetently executed. The adhesion tends to flake. A genuine patina, however, does not indicate an age like TL dating. The actual duration of a real patina may be one century or many. A Benin object made one hundred years ago but after the punitive expedition of 1897 and not worth nearly as much as a sixteenth century piece could theoretically have a similar patina.

Forgers tend to use two techniques. They corrode the new copper-alloy with chemicals to achieve the correct color patina. They also apply the correct minerals to the surface of the metal with a binding compound (Craddock 1985: 5), making detection difficult. Some may be loosened with an organic solvent, and some fluoresce when studied with x-ray diffraction, but not all Craddock [4]. One achieved a very nice looking patina by decoratively placing a Benin memorial head in a well watered section of his garden. Cutting of the copper-alloy cast or polishing usually separates genuine from fake, but rare is the collector who will allow this.

Patination chemicals are widely available and used by artists commissioned to produce large memorial statues, for instance. There are many formulas available from art chemical firms. The casters in Benin also have their formulas that do the same thing. One is a simple mixture of engine oil, battery acid and lime juice, applied numerous times. Cooking oil including palm oil may be substituted for engine oil to alter the tint of the casting.

\section{Age information}

Analysis of materials used to manufacture objects can provide age information in two different ways: (1) comparison of a known source or comparison with genuine material known to have been used at the same time as the object supposedly belongs Craddock [4] or a comparison of manufacturing techniques, and (2) evidence with the metal that it is ancient or modern. Analysis of the metal used to cast the copper-alloy is thought to provide some information about the age of the piece. Studies have been done to determine sources of the metals used in the castings and may determine trade connections Craddock [4].

Benin copper-alloys are not strictly bronze or brass. Most Benin 'bronzes' were actually copper-alloy brasses, a mixture of copper and small amounts of zinc. Over time, zinc became a larger component of the Benin copper-alloys Craddock and Picton [5], (Werner and Willett 1975), Willett and Sayre [9], Willett, Torsney and Ritchie [10]. Artisans began adding more lead and tin. There are a number of other impurities: nickel, silver, cadmium, etc (Werner and Willett 1975), Willett and Sayre [9]. Those studying the metal content of Benin copper-alloys believe that these can be dated by examination of how the percentages of copper, zinc, lead, and tin change over time.
Metal alloys (mixtures of different types of metals, such as copper, lead, tin, and zinc) contain impurities. These impurities are other metals like silver, bismuth, nickel, arsenic, or antimony. They occur naturally in the main metals of the alloys and are not removed by the smelting process or by the process to make the bronze. The concentrations of these impurities can vary from a few percentage points (a lot) to parts per million (trace) Craddock [4]. Sometimes the presence of these impurities shows the geographic origins of the main alloy components (Duboscq). Some metals found on earth like iridium only come from meteorites. Another rare element, indium, has allowed French researchers to trace silver's arrival in sixteenth century Spain from Peru's Potosi mines (Ross 2000). Sometimes the presence of the impurities can show fakes. Metals like aluminum are not commonly found in ancient metals.

\section{Spectroscopy}

Spectroscopy techniques analyze the absorption or emission of electromagnetic radiation by atoms or molecules. Atomic absorption spectroscopy (AA), and atomic emission spectroscopy (AES) are very straightforward techniques used for a variety of analyses from testing factory wastewater to analyzing metal plating baths. Like all the previous techniques, atomic absorption and atomic emission utilize the individual properties of each atom or molecule studied. In atomic absorption, an element is vaporized by an acetylene or nitrous oxide flame. It is then bombarded with light at a wavelength that specifically excites the element or molecule to be studied. This causes the electrons in that element to jump from their normal energy levels to excited levels. The amount of light absorbed is dependent upon the concentration of the specified element in the sample.

AES is very similar. The electrons in the element being studied are vaporized at temperatures of about $8000 \mathrm{C}$ in an argon flame. The electrons jump into the excited energy levels. They do not stay in these excited levels for very long and when they decay to a lower energy level, light is given off at a wavelength unique to that atom or molecule. That wavelength of light is measured when the electrons return to their normal energy levels. The amount of light emitted is proportional to the concentration of the element being studied.

How are these amounts of light converted into a concentration? Standards of known concentrations are run through the AA or AES before the unknown samples. From these standards, a working curve is created. These 'calibrate' the instrument.

When testing metal content, a sample is run as slurry, as a solid, or as a liquid (the metals are dissolved in an acid such as hydrochloric or nitric and water). After the standards are run and the sample is run, a check standard is run through the instrument. This known amount is run as if it were a sample. If the instrument measures the check within a certain percentage of its known amount, the run is considered a success. For example, if nickel is the element being analyzed, a sample is prepared containing a known amount of nickel. This amount will be close in concentration to the amounts in the unknown sample. The bronze with ID \# IIIC8075 analyzed 
by 0 Werner was found to have $0.07 \%$ nickel (Werner 1978, 1980). Therefore, the standard prepared to run at the end of the process could have $0.1 \%$ nickel. If the sample is run and between $0.095 \%$ and $0.105 \%$ nickel is found, the run would be considered successful. These numbers are an acceptable variation. If the sample is run and $0.90 \%$ is found, the entire process is repeated. The numbers found for the unknown samples (in this case $0.07 \%$ ) could be incorrect as well. AA and AES are highly accurate and precise methods for metal analysis. After the analyses are complete, the concentrations found are compared to the metal concentrations of other copper-alloys.

Recently, scientists have suggested that it is more valuable to study the content of these bronzes/brasses/copper-alloys, and they ask specific questions

. Does this casting represent an early alloy? Does this impurity indicate copper origin? A group of scientists decided to study the ratios of lead, zinc, and tin in bronze/brass memorial heads. They plotted the percentages on equilateral triangles and compared the results with an extensive stylistic study done by Benin expert, Philip Dark. Based upon his chronologies Dark [11], a high correlation in metal concentrations was observed among Dark's groups of copperalloys. Some overlap between groups was observed but determined to be limited.

Metals Analysis. Many labs continue to use metals analysis to date Benin bronzes. Metals analysis is quite straight forward and the numbers obtained are highly accurate. As the above group did, testing labs compare the concentrations of metals found to the groups established by Philip Dark. From these comparisons, an age for the copper-alloy is determined Willett [10].

Many, many difficulties arise when using metal content to date Benin bronzes. To start with, the sources of the metals are wide and varied. Not only was the metal collected from many different areas of West Africa, it is very likely that old pieces were melted down and reused. Benin copper-alloys are alloyed with zinc. This process introduces more lead into the metal than naturally occurred. Sometimes lead was even deliberately added to 'bronze' metals Craddock [4]. And, for example, the sources of lead in West Africa are numerous, thus preventing identification of lead sources.

Extensive metal analysis of different bronzes had shown that the Benin pieces' content changed from "true brass to bronze" over time Craddock [4]. It is now generally agreed that zinc content increased with time. Zinc was not found in the earliest bronzes, presixteenth century. Changes in the making of copper-alloys allowed the gradual increase of zinc from the fifteenth to the eighteenth centuries. "The variation in zinc content between contemporary metalwork is too great for the data to be used to date individual objects." Craddock [4].

There are, however, limits that do appear to work. Now, it is generally agreed that a copper-alloy with no more than $28 \%$ zinc can be dated before the sixteenth century and a copper-alloy with no more than $33 \%$ zinc can be dated earlier than the nineteenth century. Even this deadline is not absolute, because of those pieces that have been melted down and reused; a small amount of zinc can be lost during the heating process. Thus, its percentage can change and the 'deadline date' no longer applies.

For those who hoped to study trade connections, metal analysis of copper proves to be disappointing. "The composition of copper depends far more on geology than geography" Craddock [4]. Thus, copper found hundreds of miles apart could be quite similar whereas copper found separated by feet could be very different.

The greatest difficulty in using metals analysis, though, lies in the fact that there are no standards to compare against. There are no absolutes about copper concentrations, or lead concentrations. Even the trace elements do not indicate any sort of age range. The actual metal concentrations of many known Benin bronzes are extremely varied. And aside from the two accepted limits of zinc content, there is no other agreed upon concentration of any of the metals found in the bronzes that give any satisfactory indication of age. Not even Dark's chronologies have stood up to researchers using them to date a single casting instead of groups of castings. At present, the best a researcher can do is to prove a piece fraudulent if it contains some impurity, such as aluminum, that it would not likely contain had it been made in antiquity.

\section{1opb Lead isotope}

Recently the ${ }^{21} \mathrm{opb}$ test has been used for authenticating for lead-bearing objects based "on the disturbance of the radiocarbon equilibrium of the Uranium 238 decay chain" Pernicka [12]. The naturally occurring lead isotope ${ }^{210} \mathrm{~Pb}$ is mostly used to date aquatic sentiments and peat bogs (Kotarba et al. 2002) and may assist with sampling in both marine and freshwater system Sikorski and Bluszcz [13]. The radioactive isotope ${ }^{210} \mathrm{~Pb}$ present in the sediments of water reservoirs is formed in the sediment itself from the decay of ${ }^{210} \mathrm{~Pb}$ in the $\mathrm{U}$ series or from decay of that isotope outside the reservoir. The process of decay is called radioactive equilibrium or secular equilibrium. In these cases, the decay of uranium on the earth's crust releases the gas radon. This gas produces $210 \mathrm{~Pb}$ by decay in the atmosphere. The lead isotope enters the earth's crust or water through precipitation. Applied to the lead in brass castings, in most rocks or slag that contain trace elements of uranium, the secular equilibrium of the decay chain for uranium contain elements with different metallurgical conditions are disturbed during the smelting process.

As Pernicka [12] have shown, in their evaluation of a collection of Benin brasses, most of the tested artifacts showed that the radioactivity of ${ }^{21} \mathrm{opb}$ indicated objects of recent manufacture. Other signatures of a contemporary casting process included the presence of modern additive in the alloys, a uniform type of artificial corrosion applied to make the objects appear older than they were, and one suspects, identifications made on stylistic criteria. In any case, ${ }^{21} \underline{\mathrm{Pb}}$ is useful for ascertaining objects made only within the last 100 years. This is because ${ }^{21} \mathrm{~Pb}$ decreases following the radioactive decay law, with a half-life time of 22.26 years. Hence the lead-210 method is often used for dating young sediments and to determine sedimentation states (as at recently constructed dams and reservoirs). In the lost-wax casting method for Benin brass 
objects, as a result of the smelting process, the ${ }^{21} \mathrm{~Pb}$ in the metal then decays with its own half-life of 22.26 years, as a result of the disruption caused by the process of melting the metal. In effect, no activity is measurable in castings older than a century.

\section{Testing Limitations}

A basic understanding of the techniques and the theories behind them can help the art historian and archaeologist to resolve conflicting dates and recognize conflicting results. This knowledge can also help in determining appropriate methods. Science methods are tool; they are not absolute. Scientific testing results can be invalided.

The limitations of TL dating for the Benin copper-alloys cease to be a viable option for accurate dating. Patina analysis of the Benin copper-alloys is also fraught with problems. It often cannot render a piece fraudulent or genuine. Thus, the focus is on dating the Benin copper-alloys by concentrating on the metals analysis of the pieces.

The most successful analysis may be that of the trace elements, and creating a database of all published and unpublished data. LAICP-MS (laser ablation inductively coupled plasma spectrometry) finds versatile use for trace element analysis with respect to depth in solid samples Neff [14]. It is a rapid technique "for the direct, quantitative determination of major, trace and rare-earth elements" (Jarvis and Williams: 1993:251). Basically, a laser beam is focused on a material sample surface and this generates fine particles. These laser ablated particles are excited by a secondary source of the ICPMS instrument for ionization. The excited ions are subsequently introduced to a mass spectrometer that detects elements and isotopes.

When compared to Dark's chronologies, one may then hope to find trends in the concentrations of trace elements that could lend to certain eras of production of bronzes. Willett and Sayre did this rather successfully with the memorial heads. One needs to determine if there are similarities in metal concentrations with other pieces. Further study of certain elemental concentrations such as cadmium and aluminum might also prove useful. Cadmium has a boiling point of $768 \mathrm{C}$. This is a very low boiling point. By comparison, mercury (liquid at room temperature) has a boiling point of 357. Zinc has a boiling point of 907. Gold, silver, copper, nickel, iron, and tin have boiling points ranging from 1750 to 2914 (See any quick study periodic table of the elements). The metal used for casting the bronzes must be heated to at least $800 \mathrm{C}$, above cadmium's boiling point and so above the point at which cadmium will evaporate. Cadmium was also not used in ancient solders (Craddock, 6) because of its low boiling point. Of the copperalloys tested, few actually include this impurity. In fact, according to Craddock (1985: 22), zinc is lost when a metal is recast due to evaporation. There is no literature discussing cadmium as a modern impurity; one is therefore interested in determining its presence as an indicator of a modern manufacture date. One needs to also pursue the possibility that aluminum is an impurity indicating modern manufacture. Aluminum was also not used as an additive until after the punitive expedition.
The use of ${ }^{21 \circ} \mathrm{Pb}$ has proved extremely helpful but is limited by its 100 year viability, i.e., it is a dating method that covers the past period of about 100 years due to it half-life of about 22 years. In many cases the importance is to verify or disprove identifications of copper-alloy cast art suspected to be of recent vintage. Either an object is recent (and therefore made after the 1897 British Punitive Expedition terminus ad quem, or cut-off date, that art historians employ to indicate authenticity) or it is not (in which case other methods such as stylistic analysis or a combination of stylistic analysis and some other measure need to be employed). Collectors and curators devoutly wish their Benin casting(s) predates 1897 as certainty that it was removed by members of the expedition, or removed earlier, and therefore is authentic. Of course, collectors hope for a date much older than that because age and value are partly correlated. For that, one needs to employ other methods or a combination of techniques. The recent work of Peter Junge (2007, 2008 ) is pertinent here. He combines both a stylistic analysis based on the works of Felix von Philip Dark [11], Luschan [15], Bernard Struck [16] with a scientific analysis based on TL and classification by alloy analysis. Recapitulating the various data, unfortunately he finds that the comparative analysis does not result in a clear chronology for the commemorative heads at the Ethnological Museum in Berlin that carry stylistic dates from the $15^{\text {th }}$ to $19^{\text {th }}$ centuries.

\section{What Do They Mean?}

A famous scientist once said, "In science as in love, an overemphasis on technique very like leads to impotence." Good science combines method and intuition, accommodating the objectivity of mathematics and physics that since the Enlightenment has made life synonymous with progress, to the subjectivity of literature and philosophy that since the Ancients has made it worthwhile.

Despite the common wisdom that objective science trumps subjective analysis the fact is that both science and art are necessary for an evaluation of Benin copper-alloy objects. As Craddock suggests, the approaches contain complementary information, with scientific data extending the range of information, not supplanting it (2009:3).

Numerical results are often perceived as irrefutable. The significance of a percentage lends a certain kind of precision to analysis. A figure like $28 \%$ zinc sounds so clear and concise as to seem inviolable. One wants to learn that the object of desire is a genuine $100 \%$ authenticated $16^{\text {th }}$ century Benin commemorative head.

Lab results appear stunning in their scientific virtuosity. However, concerns about reliability and validity creep in; caution is called for and clients should temper a narcissistic desire to own an authentic piece of historic cast memorialized metal. Such guarantees have created a stir, however, because what are patently recently made objects sometimes come with age authentic certification. Art historians like nearly everyone else believe in science but wonder why scientific test results are often out of whack with their own stylistic evaluations. 
The reason is very simple. The astronomer Carl Sagan once said that extraordinary claims must be supported by extraordinary evidence. This applies to any scientific endeavor. Art historians sometimes express anxiety over absolute dating methods, not just because the results of such methods often contradict their own stylistic analyses, but also because science is accurate, science doesn't lie, the observations of science are conclusive, and scientific methods supposedly transcend human failings. Art history seems trapped in a conundrum, choked by the subjectivity of its claims. But in dating Benin copper-alloy objects, the science labs that test these objects are also trapped, not so much by the certitude of their claims but by the application of those claims, and the limited use of those claims. While test results are no doubt precise, application of the results that serves the interests of curators and collectors' hopes for early time dates borders on self-delusion.

In science a distinction is made between precision and accuracy. Precision is how closely two measured values agree with each other. Accuracy is how close a measured value is to the actual true value. Measurements can be accurate but not precise and vice versa. An example from phrenology illustrates this. The male brain is larger than the female brain, based on sexual dimorphism, but this has nothing to do with intelligence in homo sapiens sapiens. However, as Steven Gould tells us in The Mismeasure of Man [17], first marbles and then, for greater precision, bird seed, provided the $19^{\text {th }}$ century anatomist Stanley Morton with the evidence he sought for proving superior male intelligence. Greater precision was achieved in the early $20^{\text {th }}$ century with cranial calipers that allowed for cross-cultural comparisons with the French, Germans and English arguing over who had the larger brains, only to blow one another's out in World War I [18-20].

The lab results are excellent, but what do they mean? Scientists and lab analysts are inclined to see what they want to see, to support what they have been told they would see, and to conclude their results are scientifically valid and therefore infallible. That is how lab equipment is designed, experiments arranged, and hypotheses tested. But error is a normal part of science, skepticism is its conscience, and control experiments uncover flaws in reasoning or measurement. For the moment, stylistic analysis, whatever the limitations, serve as that control to ensure that good science and informed art historical opinions prevail over bad science and Pascal's Wager [21-24].

\section{Acknowledgements}

None.

\section{Conflict of Interest}

No conflict of interest.

\section{References}

1. Schrenk, Janet (1991) Corrosion and Past 'Protective' Treatments of the Benin 'Bronzes' in the National Museum of African Art. Materials Research Society, pp. 805-812.
2. Lawson, Natalie (2001) Thermoluminescence Testing of Benin Bronzes. Conference Paper. $73^{\text {rd }}$ Annual Meeting of the Southwestern Anthropology Association (SWAA). San Diego, California.

3. Goedicke Christian (1994) Authenticity testing on Tanagra figures according to the thermoluminescence method (Authenticity of Tanagra figurines based on thermoluminescence methods). In Irmgard Kriseleit - Gerhard Zimmer - J. Cordelia Eule (Eds.), Citizen Worlds: Hellenistic clay figurines and reproductions in the $19^{\text {th }}$ century. Philipp von Zabern publishing house, Mainz, Germany, pp. 77-81.

4. Craddock Paul (1985) Medieval Copper Alloy Production and West African Bronze Analysis. Part I. Archaeometry 27: 17-41.

5. Craddock. Paul, John Picton (1986) Medieval Copper Alloy Production and West African Bronze Analysis. Part II/ Archaeometry 28(1): 3-32.

6. Bortolot, Victor (1994) Real or Fake? Authentification by Thermoluminescence. World of Tribal Arts 1(4): 81-83.

7. Brent, Michel (2001) Faking African Art. Archaeology 549(1): 26-29.

8. Willett Frank, Stuart Fleming (1976) Nigerian Copper Alloy Casting dated by Thermoluminescence. Archaeometry 18(2): 135-146.

9. Willett Frank, Edward Sayre (1999) The Elemental Composition of Benin Memorial Heads. Archaeometry 42: 159-188.

10. Willett Frank, Ben Torsney, Mark Ritchie (1994) Comparison and Style. An Examination of the Benin Bronze Heads. African Arts 27(3): 6067,102 .

11. Dark Philip (1975) Benin Bronze Heads: Styles and Chronology. In Daniel McCall- Edna Bay (Eds.), African Images: Essays in African Iconology. Africana Publishing Co., New York, pp. 25-103.

12. Pernicka Ernst, Roland Schwab, Nicole Lockhoff, Mike Haustein (2008) Scientific Investigations of West African Metal Castings of the Stiftung Situation Kunst. In Ernest Pernicka and Silke von Berswordt-Wallrabe (Eds.), Original-Copy-Fake? Examining the Authenticity of Ancient Works of Art: Focusing on African and Asian Bronzes and Terracottas. Mainz: Philipp von Zabern, p. 80-98.

13. Sikorski Jaroslaw, Andrzej Bluszcz (2008) Application of and Spectrometry in the $210 \mathrm{~Pb}$ Method to Model Sedimentation in Artificial Retention Reservoir. Geochronometria 31: 65-75.

14. Neff, Hector (2003) Analysis of Mesoamerican Plumbate Pottery Surfaces by Laser Ablation-Inductively Coupled Plasma Mass Spectrometry (LAICP-MS). Journal of Archaeological Science 30(1): 21-35.

15. Von Luschan, Felix (1919) The antiquities of Benin I-III. Berlin, Leipzig: Association of Scientific Publishers Walter de Gruyter.

16. Struck Bernard (1923) Chronologie der Benin-Altertümer. Zeitschrift für Ethnologie 55: 113-166.

17. Gould, Steven (1981) The Mismeasure of Man. Norton, New York.

18. (2002) Personal phone correspondence.

19. Nico Broers (2009) Scientific Investigation of Copies, Fakes, and Forgeries. Butterworth-Heinemann, Oxford, UK.

20. Fage, John (1961) An Introduction to the History of West Africa. Cambridge University Press, Cambridge, UK.

21. (1994) Benin Royal Art Surfaces Past and Present. J. Paul Getty Museum and the Getty Conservation Institute, p. 51-62.

22. Werner Otto (1970) Metallurgische Untersuchungen der Benin Bronzen des Museums fur Volkerkunde, Berlin. Teil 1.Beitrag zur Systematik der Benin-Legierungen. Baessler-Archiv N.F. 18(1): 71-153.

23. Werner Otto (1978) Metallurgische Untersuchungen der Benin Messinge des Museums für Völkerkunde, Berlin. Teil 2. Beitrag zur Frage der Datierung und der Herkunft des Rohmaterials. Baessler-Archiv N.F 26(2): 333-439. 